Intecoms: Journal of Information Technology and Computer Science

Volume 1 Nomor 2, Desember 2018

e-ISSN : 2614-1574

p-ISSN : 2621-3249

DOI : https://doi.org/10.31539/intecoms.v1i2.289

\title{
SISTEM INFORMASI ONLINE PADA DIREKTORAT TAHANAN DAN BARANG BUKTI POLDA SUMATERA BARAT DENGAN MENGGUNAKAN BAHASA PEMOGRAMAN PHP DAN MYSQL
}

\section{ONLINE INFORMATION SYSTEM IN DIRECTORATE OF PRISONER AND EVIDENCE OF POLDA WEST SUMATERA USING PHP AND MYSQL}

\author{
Ahmad Junaidi \\ Universitas Putra Indonesia YPTK Padang \\ ahmad junaidi@upiyptk.ac.id
}

\begin{abstract}
The rapid development of science and technology has encouraged humans to find and implement new methods or methods in monitoring and controlling data processing systems so that they can run smoothly. The ability and speed of computers in processing data over and over again and with very large amounts is no doubt to produce reports needed in the strategic decision making process. So that at this time many companies and government agencies are using computer technology to help solve their data processing problems. This study aims to review the extent of existing procedures and can present information reports obtained. And develop a new information system by further refining the old system to achieve work efficiency. At the Directorate of Detention and Evidence (DITTAHTI) of the West Sumatra Regional Police, the processing of prisoner data and items of evidence has often been carried out, but has not yet obtained optimal results. This is due to the use of information technology that is still lacking and is still being implemented offline and manually by the municipal and district police. Optimization of data processing is needed so that the integrity, access rights and availability of data can be maintained properly. Application system that will be proposed later is PHP MYSQL. All data entry will be processed in a Database. Varied data will be more easily and quickly processed in a well-organized system.
\end{abstract}

Keywords: Information Systems, Directorate of Detention and Evidence, PHP, MYSQL

\section{ABSTRAK}

Perkembangan ilmu pengetahuan dan teknologi yang sangat pesat telah mendorong manusia untuk mencari serta mengimplementasikan cara atau metode-metode baru dalam pengawasan dan pengendalian system pengolahan data agar dapat berjalan lancar. Kemampuan dan kecepatan computer dalam mengolah data yang berulang-ulang dan dengan jumlah yang sangat besar sudah tidak diragukan lagi untuk menghasilkan laporan-laporan yang dibutuhkan dalam proses pengambilan keputusan strategis. Sehingga pada saat sekarang ini telah banyak perusahaan maupun instansi pemerintah meggunakan teknologi computer guna membantu pemecahan masalah pengolahan data mereka. Penelitian ini bertujuan untuk meninjau sejauh mana prosedur-prosedur yang ada dan dapat menyajikan informasi laporanlaporan yang diperoleh. Dan mengembangkan suatusistem informasi yangbaru dengan cara lebih menyempurnakan sistem lama untuk tercapainya efisiensi kerja. Pada Direktorat Tahanan dan Barang Bukti (DITTAHTI) Polda Sumatera Barat proses pengolahan data tahanan dan barang bukti barang telah sering dilakukan, namun belum memperoleh hasil yang optimal. Hal ini disebabkan penggunaan teknologi informasi masih sangat kurang dan masih dilaksanakan secara offline dan manual oleh Polres kota dan kabupaten. Optimalisasi pengolahan data sangat diperlukan agar integritas, hak akses serta ketersediaan data dapat terjaga dengan baik. Sistem Aplikasi yang akan diusulkan nantinya adalah PHP MYSQL. Semua entry data tersebut akan diolah dalam sebuah Database. Data beraneka ragam itu akan semakin mudah dan cepat diolah dalam sebuah sistem yang tersusun dengan baik.

Kata Kunci: Sistem Informasi, Direktorat Tahanan dan Barang Bukti, PHP, MYSQL 


\section{PENDAHULUAN}

Menurut Mulyani (2016) Sistem adalah kumpulan dari dua atau lebih komponen yang saling bekerja dan berhubungan untuk mencapai tujuan tertentu. Dia juga berpenapat bahwa perusaahan adalah sebuah sistem yang terdiri dari beberapa departremen yang bertindak sebagai susbsitem yang membentuk sistem perusahaan tersebut. Sedangkan pendapat lain mengatakan sistem adalah suatu jaringan kerja dari proosedur-prosedur yang saling berhubungan, berkumpul bersama-sama untuk melakukan suatu kegiatan atau untuk meyelesaikan suatu sasaran tertentu.

Sistem informasi adalah suatu sistem di dalam suatu organisasi yang mempertemukan kebutuhan pengolahan transaksi harian, mendukung operasi, bersifat manajerial dan kegiatan strategi dari suatu organisasi dan menyediakan pihak luar tertentu dengan laporanlaporan yang diperlukan. (Sutabri, 2012).

PHP singkatan dari Hypertext Preprocessor adalah sebuah bahasa pemograman yang berbentuk scripting, yang digunakan untuk membuat halaman web yang dinamis walaupun tidak tertutup kemungkinan untuk digunakan pemakai lain (Betha Sidik \& Husni I. Pohan, 2010). Web base programming, pada umumnya menggunakan bahasa pemrograman php, dengan pasangan aplikasi pengelola database mySQL.

MySQL termasuk Relational

Database Management System (RDBMS) yaitu hubungan antar tabel yang berisi data-data pada suatu database. Database pada MySQL terdiri dari tiap-tiap tabel. Setiap tabel mempunyai kolom, baris, serta record untuk menyimpan data. Tabel-tabel tersebut di link oleh suatu relasi yang memungkinkan

untuk mengkombinasikan data dari beberapa tabel ketika seorang user menginginkan menampilkan informasi dari suatu database. Penggunaan MySQL biasanya dipadukan dengan menggunakan program aplikasi PHP, karena dengan menggunakan kedua program tersebut telah tersebut telah terbukti akan kehandalannya dalam menangani permintaan data (A Puspitosari, Heni 2011).

Pada Direktorat Tahanan dan Barang Bukti (DITTAHTI) Polda Sumatera Barat proses pengolahan data tahanan dan barang bukti barang telah sering dilakukan, namun belum memperoleh hasil yang optimal. Hal ini disebabkan penggunaan teknologi informasi masih sangat kurang dan masih dilaksanakan secara offline dan manual oleh Polres kota dan kabupaten. Optimalisasi pengolahan data sangat diperlukan agar integritas, hak akses serta ketersediaan data dapat terjaga dengan baik.

Dengan pengolahan data secara komputerisasi diharapkan dapat mengatasi permasalahan dan proses kerja akan lebih cepat serta informasi yang dihasilkan akan lebih memuaskan serta tepat sasaran. Banyak kajian tentang pentingnya pengolahan data berbasis web maupun desktop agar dapat digunakan dengan cepat, efisien seperti Arman (2016) dan Lestari (2015) merancang sistem informasi pengolahan data pendudukan, Nozomi dan Hamzah (2018) juga merancang pengolahan data surat izin barang pada Dinas Perhubungan Kabupaten Lima Puluh Kota, Begitu juga pengolahan data pada sektor pendidikan yaitu pengolahan data perpustakaan (Tiningsih, 2011), pengolahan data kegiatan pengabdian dan penelitian kepada masyarakat (Hamzah, 2016). Di sektor kesehatan yaitu pengolahan data posyandu (Musliani dkk, 2017), dan juga pada 
sektor meteorology terkait pengolahan data cuaca pada suatu wilayah (Asynuzar, 2014., Khambali dkk, 2017).

Adapun tujuan dari penelitian ini dilakukan adalah untuk meninjau sejauh mana prosedur-prosedur yang ada dan dapat menyajikan informasi laporanlaporan yang diperoleh. Dan mengembangkan suatusistem informasi yangbaru dengan cara lebih menyempurnakan sistem lama untuk tercapainya efisiensi kerja.

\section{METODE PENELITIAN \\ Data Penelitian}

Data-data penelitian merupakan data-data terkait data tahanan dan barang bukti di direktorat tahanan dan barang bukti Polda Sumatera Barat. Data penelitian diambil dengan melakukan observasi pada kantor tersebut dan dengan melakukan wawancara terkait pengolahan data tahanan dan barang bukti. Kemudian peneliti melakukan studi literatur untuk mendukung literatur penelitian agar hasilnya sesuai dengan yang diharapkan.

\section{Tools Yang Digunakan}

Penelitian ini dalam pembuatan sistemnya menggunakan software macromedia dreamweaver untuk bahasa pemograman PHP, dan MYSQL sebagai tempat penyimpanan data yang akan digunakan.

\section{Metode Pengembangan Sistem}

Dalam pengembangan sistem pengolahan data tahanan dan barang bukti ini menggunakan metode waterfall yang bekerja dengan sistematis dan terstuktur secara bertahap dalam pembangunan sistem (Boehm, 1988).

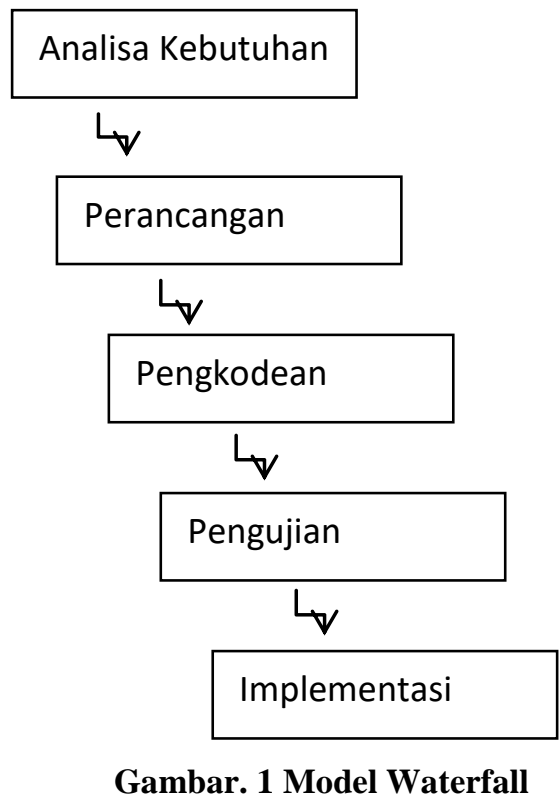

Pada gambar diatas adalah tahapan tahapan dalam mengembangan sistem pengolahan data tahanan dan barang bukti. Adapun langkah-langkah nya adalah :

Analisis Kebutuhan : Langkah awal yang harus dilakukan yaitu menidentifikasi kebutuhan-kebutuhan apa saja yang dibutuhkan dalam membangun suatu sistem pengolahan data tahanan dan barang bukti dengan cara melakukan observasi dan wawancara.

Perancangan : Langkah yang kedua ini terkait perancangan yang akan dibuat dalam pembangunan sistem yang sesuai kebutuhan.

Pengkodean : Langkah ke tiga yaitu melakukan pengkodean sistem sesuai dengan perancangan yang dirancang sebelumnya. Pengkodean ini menggunakan bahasa pemograman PHP dan MYSQL untuk penyimpanan data.

Pengujian : Langkah ke empat yaitu melakukan test atau pengujian terhadap sistem yang telah dibangun agar sesuai dengan yang diharapkan.

Implementasi : Langkah yang terakhir yaitu penerapan aplikasi pengolahan data tahanan dan barang 
bukti pada Direktorat Tahanan dan Barang Bukti Polda Sumatera Barat.

\section{HASIL DAN PEMBAHASAN \\ 1. Kebutuhan Sistem}

Untuk dapat akses sistem yang telah dibangun, standar minimal hardware yang dapat digunakan adalah processor intel core i3 dan memory $1 \mathrm{~GB}$.

\section{Context Diagram}

Context Diagram merupakan gambaran secara global atau umum dari sistem yang dirancang secara logika tanpa mempertimbangkan lingkungan fisik tempat data itu mengalir atau tempat data itu disimpan. Keuntungan dari context diagram adalah memudahkan pemakai untuk mengerti sistem yang akan dikembangkan. Berikut ini adalah gambar context diagram pada Direktorat Tahanan dan Barang Bukti Polda Sumbar, dapat dilihat pada gambar berikut:

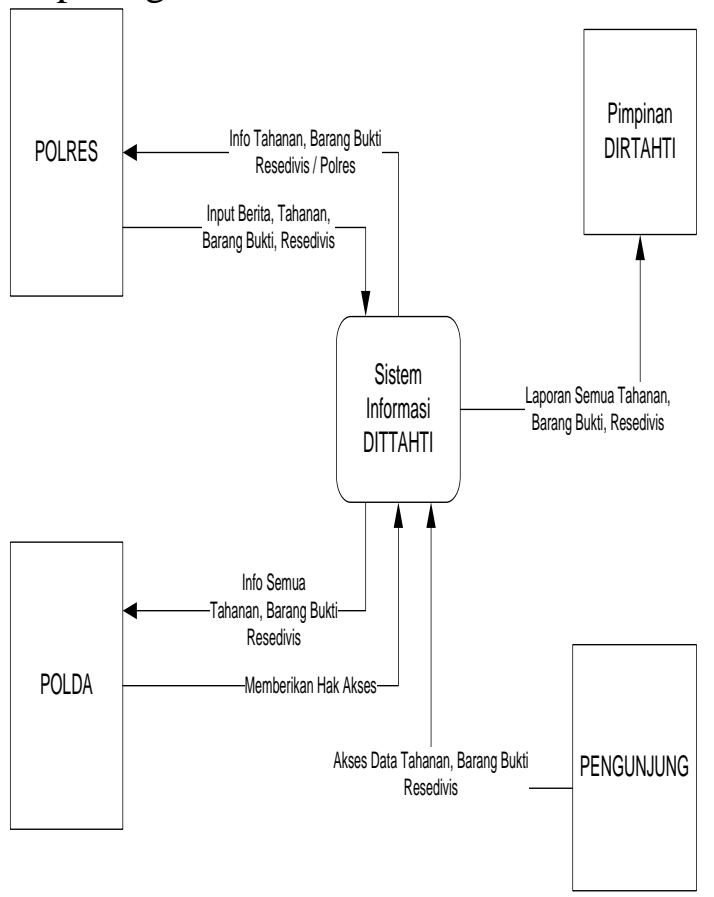

Gambar. 2 Context Diagram Pada Direktorat Tahanan dan Barang Bukti Polda Sumbar

\section{Data Flow Diagram (DFD)}

Data Flow Diagram digunakan untuk menggambarkan sistem secara logika yang akan menunjukkan bagaimana secara logika fungsifungsi sistem informasi akan bekerja. DFD merupakan alat yang digunakan pada metodologi pengembangan sistem yang terstuktur (structure analysis design). DFD level 0 merupakan penjabaran context diagram. Adapun Data Flow Diagram (DFD) dari sisitem informasi tahanan dan barang bukti Polda Sumatera Barat adalah seperti terlihat pada gambar berikut:

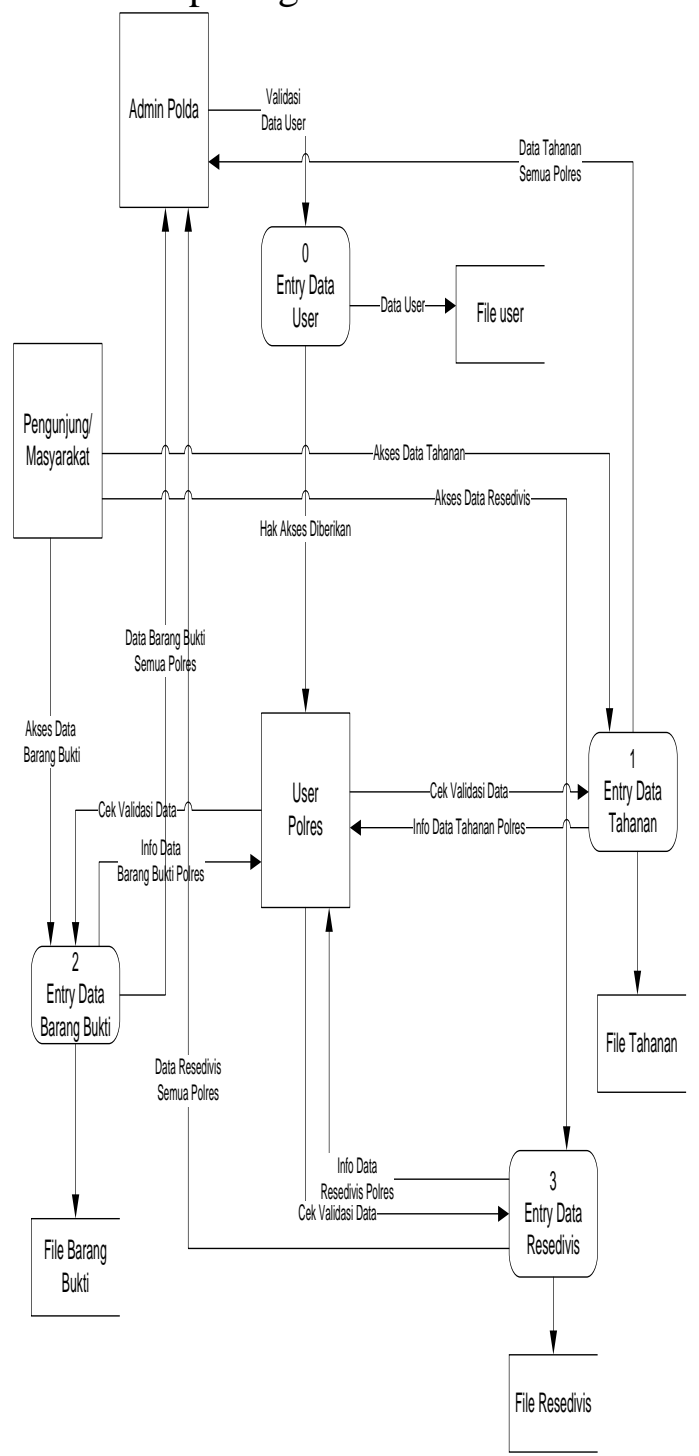

Gambar. 3 DFD Pada Direktorat Tahanan dan Barang Bukti Polda Sumbar 


\section{Entity Relationship Diagram (ERD)}

Entity Relationship Diagram adalah suatu model jaringan kerja (network) yang menguraikan susunan data yang distore dari sistem secara abstrak. Entity Relationship Diagram menunjukkan hubungan antar entity didalam sistem. Bentuk ERD yang dirancang terlihat dalam gambar berikut :

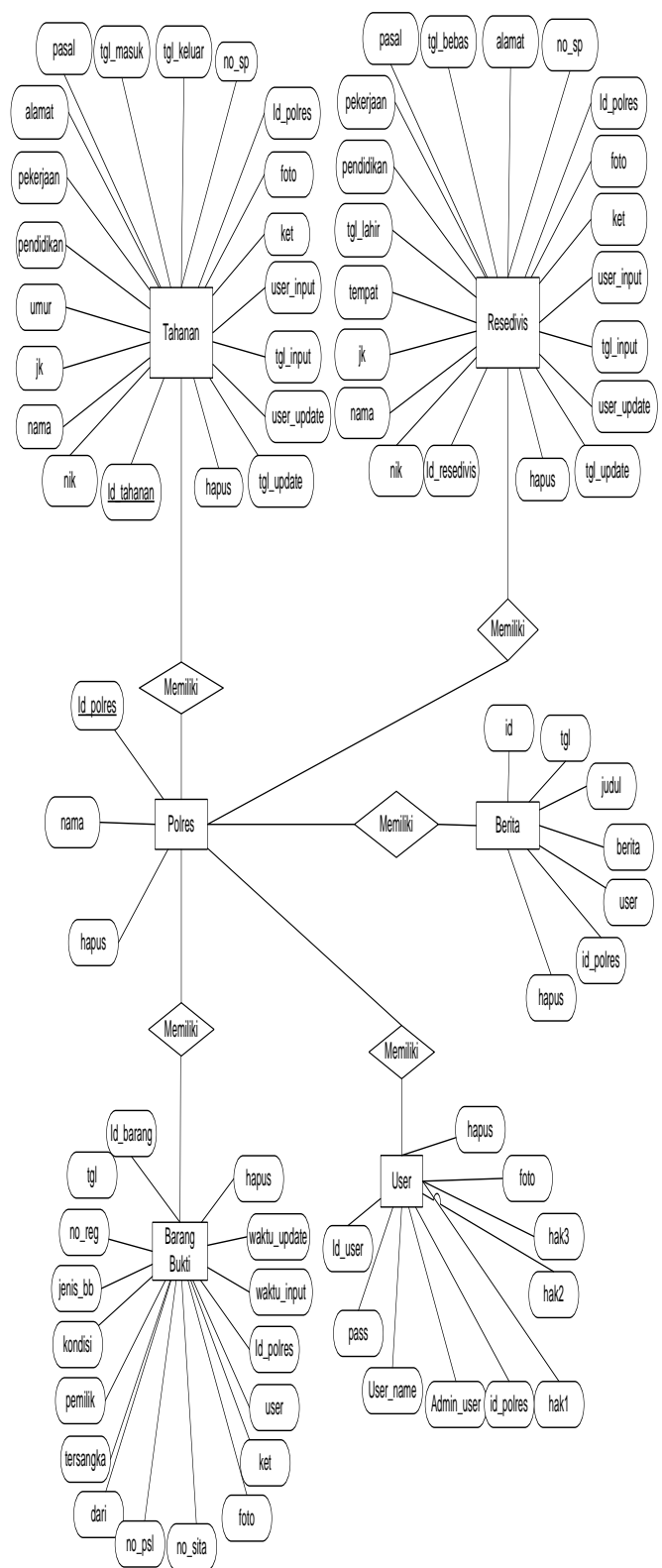

Gambar 4. ERD Pada Direktorat Tahanan dan Barang Bukti Polda Sumbar

\section{Struktur Program}

Struktur Program merupakan gambaran umum dari program yang dirancang oleh penulis, dimana menggambarkan aliran-aliran dan bagian-bagian program yang akan diterapkan pada Direktorat tahanan dan barang bukti Polda Sumbar. Disini akan diterapkan suatu program aplikasi yaitu PHP MYSQL yang akan menampilkan laporan yang sudah diinputkan datanya pada program entry dan laporan sehingga akan diperoleh data yang akurat dan benar. Untuk mempelajari hubungan tersebut dapat dilihat pada gambar :

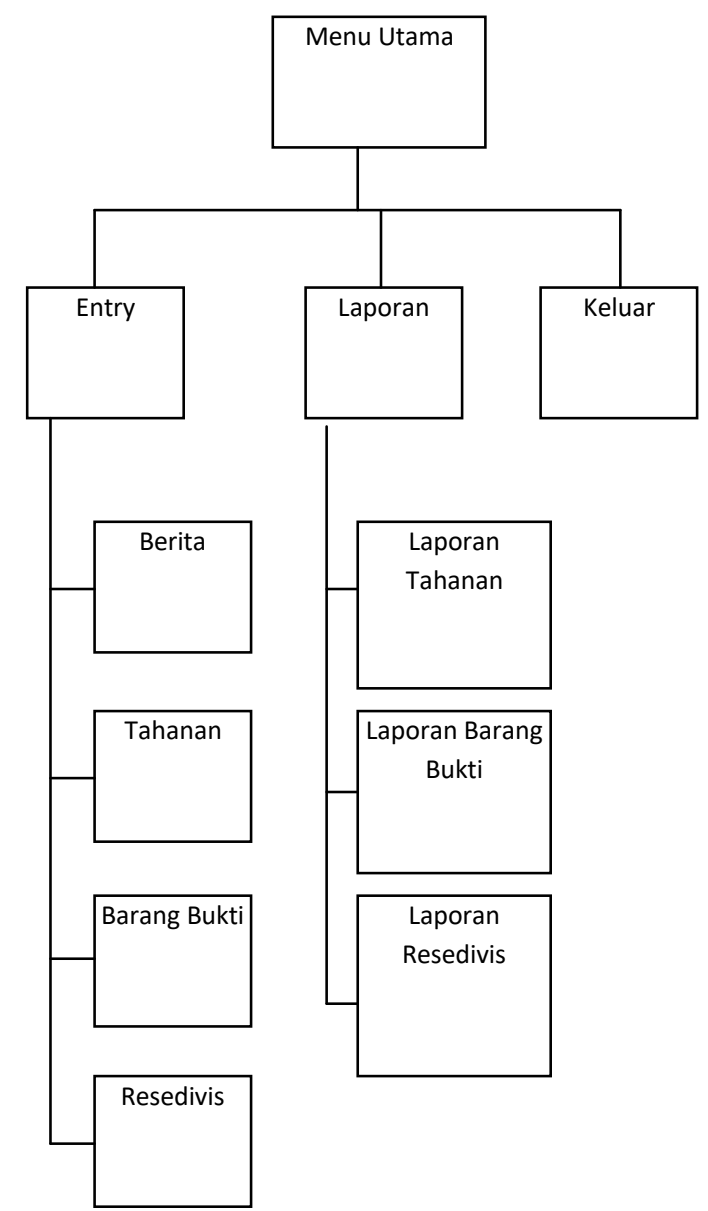

Gambar. 5 Struktur Program Pada Direktorat Tahanan dan Barang Bukti Polda Sumbar 


\section{Implementasi Sistem}

a. Login Admin

Dimana admin harus memasukkan Username dan Password untuk dapat masuk ke menu utama dari program aplikasi. Seperti yang terlihat pada gambar berikut ini:

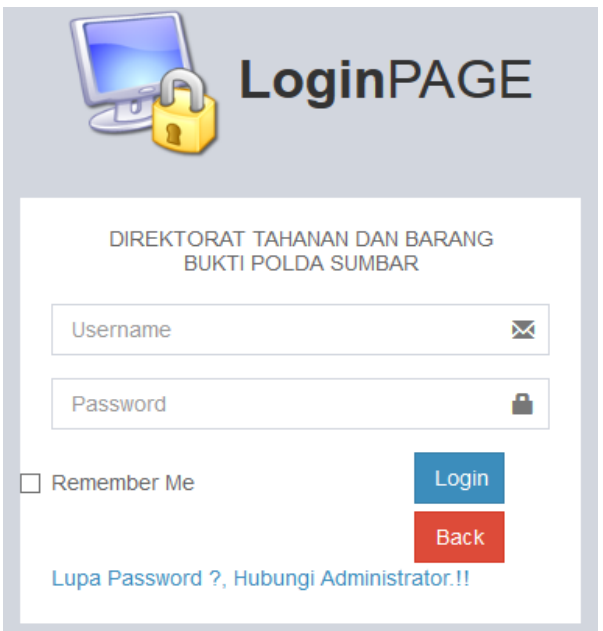

Gambar. 6 Tampilan Login

b. Menu Utama

Menu utama menyajikan berbagai pilihan aplikasi yang dapat digunakan untuk mengentrikan data ke dalam database serta mengakses data.

Data tersebut kembali untuk dijadikan informasi melalui query yang telah dicodekan dan melalui proses seleksi. Berikut gambar tampilan menu utama,dapat dilihat pada gambar dibawah :

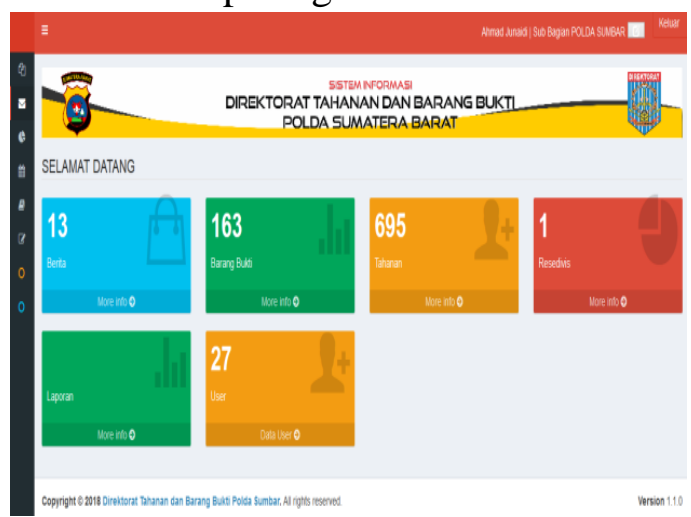

Gambar. 7 Tampilan Menu Utama c. Sub Menu Entry Data

Sub Menu Entry Data merupakan bagian dari Menu Utama. Tampilan dari Sub Menu Entry Data dapat kita lihat pada gambar berikut :

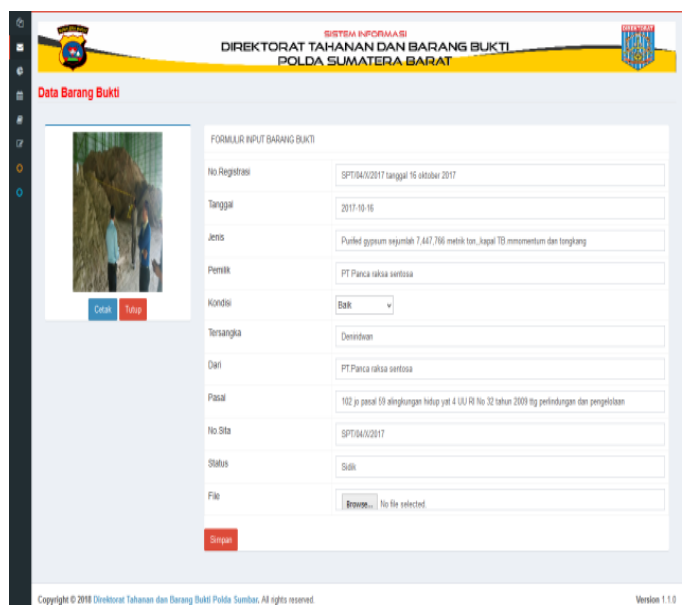

Gambar 8. Tampilan Menu Entry Data

d. Sub Menu Laporan

Dalam Sub Menu ini berisikan tentang laporan perbulan dan pertahun dari data tahanan dan barang bukti yang telah di entrykan dan diverifikasi. Seperti yang terlihat pada gambar berikut:

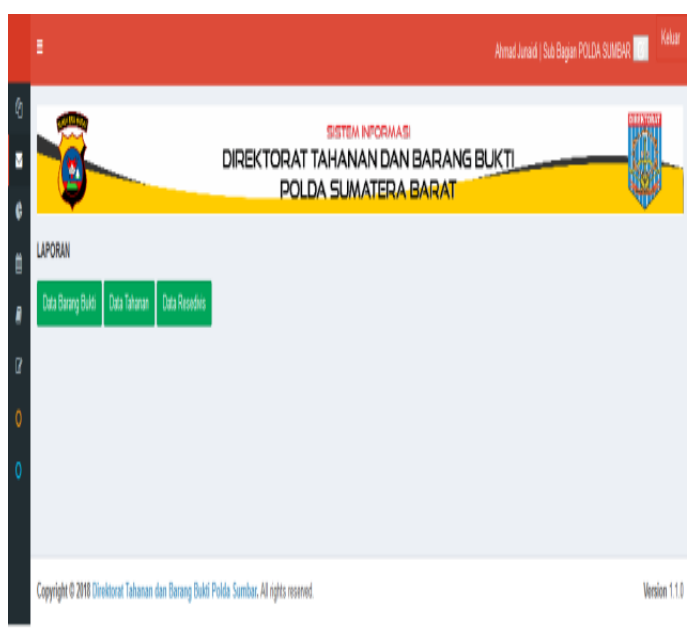

Gambar. 9 Tampilan Menu Laporan

e. Sub Menu Entry Data Tahanan

Sub menu entry data tahanan adalah tempat pengentryan data tahanan yang 
sudah diverifikasi datanya. Tampilan sub menu entri data tahanan dapat dilihat pada gambar berikut :

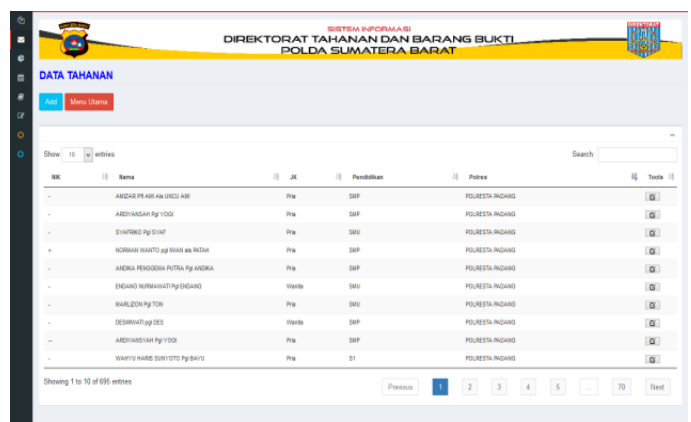

Gambar 10. Tampilan Entry Data Tahanan

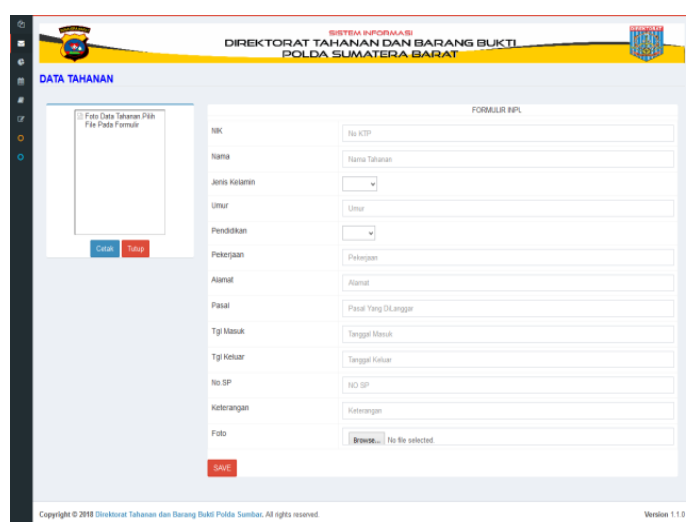

Gambar 11. Tampilan Entry Data Tahanan

f. Preview Laporan Bulanan

Berikut ini adalah preview hasil cetak laporan bulanan data barang bukti. Seperti pada gambar berikut:

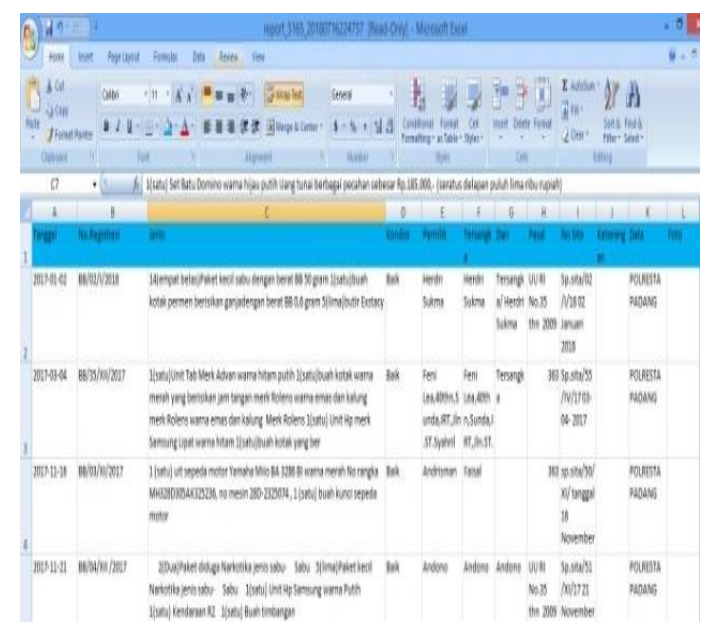

Gambar 12. Tampilan Preview Laporan Bulanan

\section{SIMPULAN}

Dari uraian dan penjelasan yang telah dikemukakan pada bab-bab sebelumnya, maka dapat ditarik kesimpulan dari penelitian yang telah dilakukan dan saran-saran yang diharapkan bermanfaat bagi pembaca pada umumnya dan bagi pihak yang bersangkutan. Kesimpulan yang dapat dikemukakan antara lain :

1. Bahasa pemrograman PHP MYSQL merupakan salah satu program aplikasi yang digunakan untuk memecahkan permasalahan untuk mempermudah pengolahan data tahanan dan barang bukti di Direktorat Tahanan dan Barang Bukti Polda Sumatera Barat.

2. Keamanan data dapat lebih terjamin dengan menggunakan sebuah database dan hak akses yang diatur dengan seksama, sehingga informasi yang diinginkan dapat diketahui dengan lebih cepat dan akurat bagi pihak yang bersangkutan.

3. Informasi tentang tahanan dan barang bukti dapat diketahui lebih cepat, akurat, dengan penggunaan sistem komputerisasi yang optimal.

4. Sistem yang baru ini dapat meminimalkan waktu dalam proses pembuatan laporan dan laporan yang dihasilkan menjadi lebih efektif dan efisien.

\section{DAFTAR PUSTAKA}

Arman, S. (2016). Sistem Informasi Pengolahan Data Penduduk Nagari Tanjung Lolo, Kecamatan Tanjung Gadang, Kabupaten Sijunjung Berbasis Web. Jurnal Edik Informatika, 2(2), 163-170

Asynuzar, N. (2014). Pengembangan Aplikasi Pengolahan Data Cuaca pada Stasiun Meteorologi Maritim 
Pontianak. Jurnal Sistem dan Teknologi Informasi (JustIN), 3(1)

Boehm, B. W. (1988). A Spiral Model of Software Development and Enhancement. Computer, 21(5), 61- 72

Hamzah, H. (2016). Sistem Pengolahan Data Kegiatan Penelitian dan Pengabdian Kepada Masyarakat di Universitas Respati Yogyakarta. Scientific Journal of Informatics, 3(1), 1-10

Khambali, M., Rohayah, S., \& Somantri, O. (2017). Pembangunan Aplikasi Pengolahan Data Unsur Cuaca Pada Statiun Meteorologi Kota Tegal dengan Model Waterfall. Jurnal Informatika. Jurnal pengembangan IT(JPIT), 2(1), 3741

Lestari, S. (2015). Analisis dan Perancangan Sistem Informasi Pengolahan Data Penduduk di Kantor Kecamatan Sungai Selan Bangka Tengah. Jurnal SIFOM

Mulyani, S. (2016). Metode Analisis dan Perancangan Sistem (2nd ed.). Bandung: Abdi Sitematika

Musliani, W. L., \& Mawarni, S. (2017). Aplikasi Pengolahan Data Posyandu. Jurnal Inovtek Polbeng: Seri Informatika, 2(1), 41-47

Nozomi, I., \& Hamzah, M. (2018). Aplikasi Pengolahan Data Surat Izin Usaha Angkutan Barang pada Kantor Dinas Perhubungan Kabupaten Lima puluh Kota. Intecoms: Journal of Information Technology and Computer Science, 1(1), 110-118. https://doi.org/https://doi.org/10.3 1539/intecoms.v1i1.167

Saladin, D. (2004). Manajemen Pemasaran Analisis, Perencanaan, Pelaksanaan dan Pengendalian.
Edisi Ketiga. Bandung: CV. Linda Karya

Sidik, B., \& Pohan, H. I. (2010). Pemograman Web dengan HTML. Bandung: Informatika

Sutabri, T. (2012). Analisis Sistem Informasi. Andi. Yogyakarta

Tiningsih, E. W. T. (2011). Sistem Informasi Pengolahan Data Perpustakaan Pada SMK Negeri 1 Demak. Jurnal Teknik-Unisfat, 6(2), 89-102 